\title{
Forecasting Unsafe Level of Work Stations with Injuries Frequency Measurement Criterion: A Fuzzy Logic Approach
}

\author{
${ }^{1 *}$ Hezekiah O. Adeyemi, ${ }^{2}$ Taofeek A. Yusuf, ${ }^{3}$ Martins O. Osifeko \\ ${ }^{l}$ Department of Mechanical Engineering, Olabisi Onabanjo University, Nigeria \\ ${ }^{2}$ Mechanical Engineering Department, University of Agriculture, Makurdi Nigeria \\ ${ }^{3}$ Department of Computer Engineering, Olabisi Onabanjo University, Nigeria \\ *adeyemi.hezekiah@oouagoiwoye.edu.ng,
}

\begin{abstract}
In this study, a fuzzy-based expert system called Accident Prone Workstations Prediction Expert System (APWAPES) was developed to forecast unsafe level of work stations. APWAPES used fuzzy set theory to make decisions based on the "Total-hours-worked" and "Injury-Count" as inputs and "Workstationunsafe-ratings" as the output. Data collected from subjects in 20 workstations were run with APWAPES. The results were compared with an Existing Mathematical Model (EME). The validation result showed that there was a strong positive relationship between the EME and the developed APWAPES with a correlation coefficient of 0.710 . The t-test result for mean difference showed that EME had a statistically significantly higher level of rating $(0.60 \pm 0.30, \mathrm{SEM}=0.004)$ compared to APWAPES $(0.50 \pm 0.02, \mathrm{SEM}=0.007), \mathrm{t}(38)=$ $1.613, \mathrm{p}=0.115$. With a significance level of 0.001 at $95 \%$ confidence, the APWAPES and the EME predicted values were not significantly different. The study developed an expert system, APWAPES, which can find its applications in any work place where hazards occur and capable of helping managers of industries, to measure work places and/or activities disposed to accidents.
\end{abstract}

Indexed Terms- Injury, Unsafe, Occupation, Fuzzy, Workplace

\section{INTRODUCTION}

Work station is an appointed position for an employee to implement his or her job, and which is furnished with all the required tools and facilities. Design of work stations has lots of influences on job performance and/or comfort level of worker using them. Many studies were reported by other authors on analysing and improving ergonomics of workstation. The major focus of all the researches were to improve operator's performance and comfort on the assigned tasks [1-3]. Washington State Department of Labor and Industries [4] suggested that while employees in micro sized work places are allowed to set up their own workstation to suit the way they work, managers in those of small-to-medium sized company should evaluate all of their office jobs stations to comprehensively ensure implementation of ergonomics program to reduce accident.

According to Peden [5], accident is defined as unintended and unavoidable event which interrupts the sequence of an activity. According to the International Labor Organization [6] there are 270 million occupational accidents causing 2 million deaths. In the United States the cost of occupational injuries was estimated at $\$ 177.2$ billion, and 35 million working days were lost annually [7]. Industrial accident fatality rates were however reported higher in the developing countries than those of the industrial countries [8]. However, accident can lead to an injury. It generates pain and suffering, negative consequences to the victim's family, a possible reduction in physical capacity, and economic loss [9]. Workers are an essential part of every industry progress and critical to delivering quality products and services. It has been estimated that two-thirds of the workers of the world still work in conditions that do not meet the minimum standards set by International Labour Organization (ILO) [10]. It is costly when an employee becomes injured given both the direct costs and the loss of the valuable services provided by the employee. Development and the use of ergonomics tool is a measure by which managers in any industry can use to help prevent all categories of injuries and helps employees work more effectively, efficiently, and productively at their jobs. Occupational injuries are, in principle, preventable [11]. Among the approaches to preventing these include, developing awareness of occupational health and safety 
hazards among workers and employers, assessing the nature and extent of hazards, and introducing and maintaining effective control and evaluation measures [12].

Worksite analysis is the first step in developing solutions to potential causes of workplace injuries. This include: task analysis (looks at what each employees does on the job on a daily basis), workstation analysis (looks at the physical components of the work places), environmental analysis (examines the area surrounding the individual workstations) and organizational analysis (deals with issue such as work schedules) [4], these help to determine risk context [13]. There are however many qualitative and quantitative methods to analyze accident risk. Many mathematical models have been developed by other authors to assess workers safety and/or injuries, few of which include Krause [14], Mallet et., [15], Murray [16] and Tara-Louise [17]. Methods of fuzzy logic have also being widely used to provide a convenient way to conduct risk analyses [18]. Fuzzy Logic explains systems in terms of aggregate of numeric and linguistics. This has benefits over pure mathematical (numerical) ways because very often system knowledge is accessible in such a combination. Problems for which an exact mathematically accurate definition is deficient can often be handled by fuzzy logic. According to DeReus [19], the use of fuzzy logic clearly enables a human being to interface easier with an automated system than with mathematical models. Benefits may therefore result in all cases where human beings are involved with systems most especially for users and unlike mathematical model, a more natural system interface can be obtained in fuzzy systems where the system can directly communicate with the user via natural language terms.

Fuzzy Logic is in the form of logic used in some expert systems and other artificial intelligence applications in which variables can have degrees of truthfulness or falsehood represented by a range of values between 1 (true) and 0 (false) [20]. Fuzzy process is a combination of four sub processes: fuzzification (the membership functions defined on the severities of investigated hazards are applied to their actual values, to determine the degree of truth for each rule premise), inference (the truth-value for the premise of each rule is computed and applied to the conclusion part of each rule), composition (all of the fuzzy subsets assigned to each output variable are combined together to form a single fuzzy subset for each output variable and defuzzification (converts fuzzy value to a single number-a crisp value) [21].

Fuzzy logic has been widely used for risk assessment. To further contribute in this direction, this study attempted to develop a fuzzy logic based expert system to forecast unsafe level of work station using injuries frequency measurement criterion. The objectives are to compare the predictions outcome of the developed expert system with the outcome of using an Existing Mathematical Expression (EME) and also compare the linguistic interpretations of the two media.

\section{MATERIALS AND METHODS}

\subsection{Fuzzy logic}

This study used Fuzzy logic theory because it borrows the approach of human's legitimate thinking to establish its judgment. Trapezoidal membership function was used to convert the two input sets used into fuzzy set. Trapezoidal has greater applicability in modelling linear uncertainty problems [22]. Membership function in fuzzy logic is of different types. The most common ones are: Triangular, Trapezoidal, Gaussian, Generalized bell, $\pi$-Shaped, S-Shaped. The simplest membership functions are formed using straight lines [23]. According to MathWorks [24], the trapezoidal curve (Figure 1) is a function of a vector, $\mathrm{x}$ which depends on four scalar parameters, a, $\mathrm{b}$, c, and $\mathrm{d}$, as given by the following:

$F(x: a, b, c, d)=\max \left(\min \left(\frac{x-a}{b-a}, \frac{d-x}{d-c}\right), 0\right)$ 


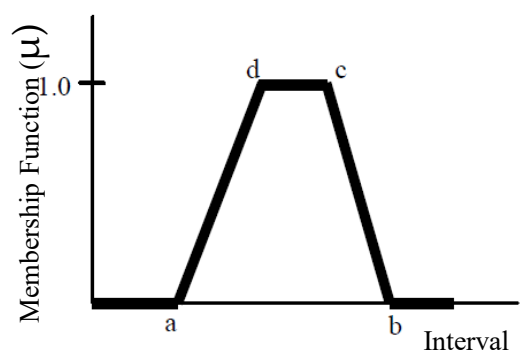

Figure 1: Typical continuous fuzzy set membership function trapezoidal

The parameters a and d locate the "feet" of the trapezoid and the parameters $b$ and c locate the "shoulders"

\subsection{Development of Accident Prone Work stations Prediction Expert System (APWAPES)}

The development of the fuzzy based APWAPES, implemented on MATLAB, comprised three steps: fuzzification of input variables and output risk value, determination of the application rules and inference method, and defuzzification of the unsafe-rating values [25].

\subsubsection{Fuzzification of input variables}

Two variables, namely "Count of injury" and "Total time worked" were selected as input variables for the system. The two variables were reported as suitable for measurement of workplace hazards rating this was expressed in the Existing Mathematical Expression (EME) [26] as:

Frequency Rate (Unsafe Rating) $=\frac{\text { Total Number of Accidents /Injuries }}{\text { Total Hours Worked }}$

From the mathematical expression (Eq. 2), accident frequency was defined as the total number of accidents per million (1000000) Man-Hours Worked. If a man-hour task in one day is 8 hours, in three working days, total Hours worked will be 24 hours. In three days, a man is not expected to sustain injury more than one time under a safe working station. Hence the highest number of expected injuries during these stretches is 1 . This may change within range $0-1$ at a decline level of 0.25 .

The level of safety of any work exercises, once the assessment of frequency Rate is decided can be categorized and determined using the model shown in Table 1.

Table 1 : Prediction Model for Work activities based on Frequency rate

\begin{tabular}{|c|c|c|}
\hline $\mathrm{S} / \mathrm{N}$ & Frequency Rate & Safety Level of Work Activities \\
\hline 1 & $\mathrm{x} \leq 0.01$ & Very Safe \\
\hline 2 & $0.01<\mathrm{x} \leq 0.02$ & Moderately Safe \\
\hline 3 & $0.02<\mathrm{x} \leq 0.03$ & Less Safe (critical) \\
\hline 4 & $0.03<\mathrm{x} \leq 0.04$ & Unsafe (Highly critical) \\
\hline 5 & $\mathrm{x}>0.04$ & Highly Unsafe \\
\hline
\end{tabular}

Source: Yusuf et al., [26]

APWAPES was developed from the authors' knowledge who detailed four (4) linguistic values for each of the input variables and the output variable as detailed in Table 2, 3 and 4.

For instance from Table 2, using figure 2, the first interval value for the linguistic 1-day working Hour, consist of two ' 0 '. The first zero is the feet of the trapezoid. The second 0 and third value (24) are the ranges of time (0-24 or 0 am to $12 \mathrm{am})$ described in Figure 1 as d-c. The range has a membership function of 1.0 , that is, $100 \%$ certainty- an international standard for 24 hours. The shoulder of the interval 24, 32 has uncertain membership function of which the range can vary from $99 \%$ to $0 \%$. This scenario can occur if a worker extends his working hour beyond 24 hours 
but the extension not recognized but counted as 24 hours by an employer.

Table 2: Output variable "Total Hours Worked"

\begin{tabular}{cc}
\hline Interval & Linguistic value \\
\hline $0,0,24,32$ & 1-day Working Hour $\left(\mathrm{WH}_{1}\right)$ \\
$24,32,56,64$ & 7-days Working Hour $\left(\mathrm{WH}_{7}\right)$ \\
$56,64,112,120$ & 14-days Working Hour $\left(\mathrm{WH}_{14}\right)$ \\
$112,120,168,176$ & 21-days Working Hour $\left(\mathrm{WH}_{21}\right)$ \\
\hline
\end{tabular}

Table 3: Input variable "Count of injury"

\begin{tabular}{cc}
\hline Interval & Linguistic value \\
\hline $0,0,1,2$ & Minimal Event (ME) \\
$1,2,4,5$ & Increased Event (IE) \\
$4,5,7,8$ & High Event (HE) \\
$7,8,10,10$ & Extremely High Event (EHE) \\
\hline
\end{tabular}

Table 4: Output variable "Unsafe-Rating"

\begin{tabular}{cc}
\hline Interval & Linguistic value \\
\hline $0,0,0.01,0.02$ & Very Low \\
$0.01,0.02,0,03,0.04$ & Low \\
$0.03,0.04,0.05,0.06$ & High \\
$0.05,0.06,0.1,0.1$ & Very High \\
\hline
\end{tabular}

\subsubsection{IF-THEN Rules and Inference Method}

Fuzzy rule and fuzzy reasoning are considered the backbone of fuzzy inference systems [27]. With the two inputs and each with four linguistic values, there are 16 (42). If-Then rules (all possible combinations of the premise linguistic values) fired into the Mamdani's inference engine of APWAPES system. Some of the rules are as follows:

If (Total-Hours-Worked is WH-1) and (Injury_Count is ME) then (Workplace-Unsafe_Rating is Very-Low)

If (Total-Hours-Worked is WH-7) and (Injury_Count is ME) then (Workplace-Unsafe_Rating is Very-Low)

If (Total-Hours-Worked is WH-14) and (Injury_Count is IE) then (Workplace-Unsafe_Rating is Low)

If (Total-Hours-Worked is WH-14) and (Injury_Count is EHE) then (Workplace-Unsafe_Rating is Very_High)

If (Total-Hours-Worked is WH-21) and (Injury_Count is HE) then (Workplace-Unsafe_Rating is High)

\subsubsection{Defuzzification of unsafe rating/value}

The 'unsafe rating'- the consequence of the expert system, was determined by inference of the fuzzy rule set using Mamdani's inference and centroid defuzzification of the fuzzy output. Mamdani's method is the most commonly employed fuzzy methodology and well suited to human input [28]. There are more defuzzification methods available but the centroid and maximum methods are more common [29], The centroid defuzzification method has been proved to be extremely accurate [30]. 


\subsection{APWAPES Validation}

\subsubsection{Data}

Twenty (20) samples including the 'total man-hour worked' and 'injury-count' obtained from the investigated accident/injuries cases of some industries as reported by Yusuf et al. (2015) was used to validate the developed expert system. The two sets of input variables were run in APWAPES. The EME as stated in (2) was also used to compute for accident frequency rating for each using the same variables and data from the 20 samples. The outcomes using the two media (APWAPES and EME) were interpreted based on the expert's rating highlighted in Table 4 and were compared.

\subsubsection{Statistical Analysis}

The predictions of APWAPES and the computed values using EME were compared using Spearman's rho correlation. The strength of correlation was determined as either weak $(0<|\mathrm{r}|$ $<0.3)$, moderate $(0.3<|\mathrm{r}|<0.7)$, or strong $(|\mathrm{r}|>0.7)$. Independent sample t-test statistics tool was used for further confirmation. The t-test evaluated the difference between the computed means of the two independent groups, APWAPES and EME.

\section{RESULTS AND DISSCUSSİON}

As shown in Figure 2, the model used two inputs of total number of hours worked and the frequency of injury recorded within the working time, fired by Mamdani's inference engine to produce output, the 'Workplace Unsafe Ratings'

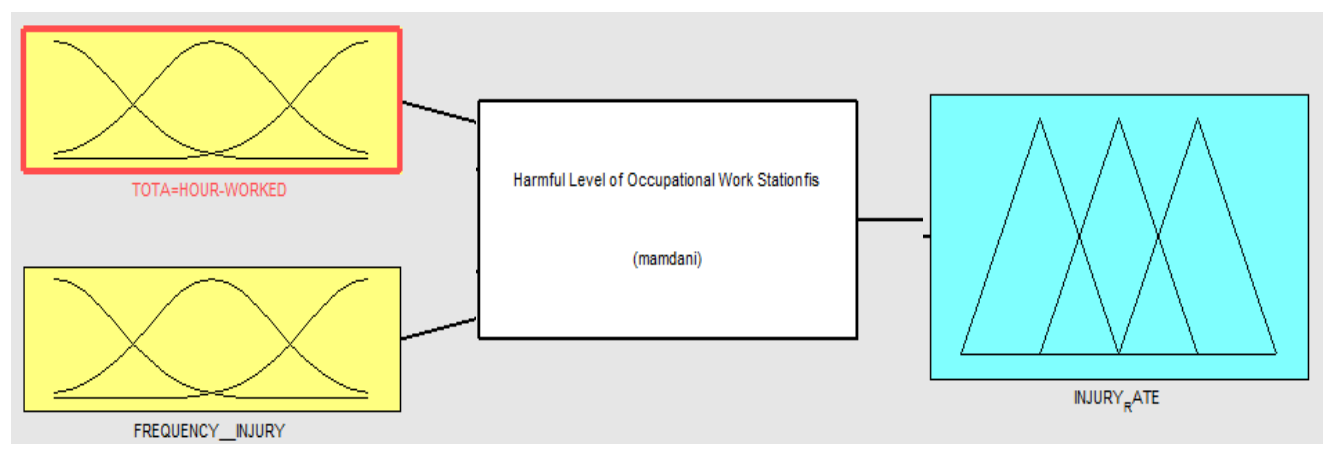

Figure 2: Fuzzy Inference System variables for APWAPES

Figures 2-6 are the membership function graphs as displayed on the user face platform of MATLAB. The graphs show all of the MFs related to the inputs and the output variables for the model. In figure 2, the trapezoidal MF has four variables. The intervals and all linguistic interpretation are as mentioned in Table 3. In like manner, Figure 3 and 4 display the intervals and all linguistic interpretations of the second input and that of the output variables respectively.



Figure 3: Membership function for the input variable "Injury-Count"

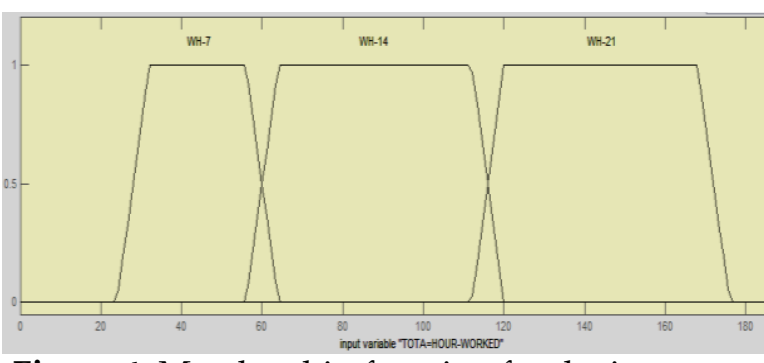

Figure 4: Membership function for the input variable "Working Hours" 


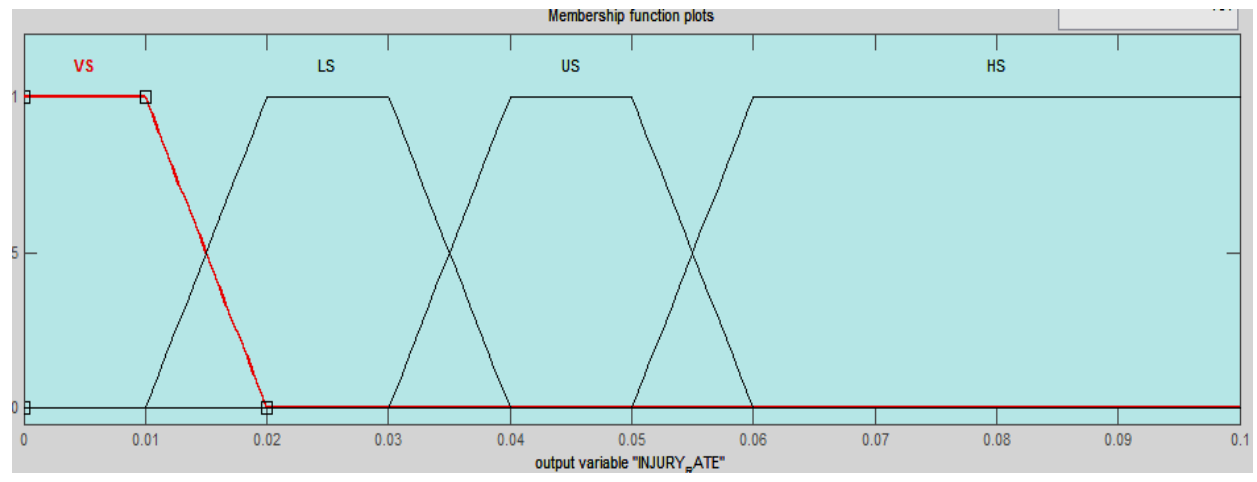

Figure 5: Membership function for the output variable "Unsafe Ratings"

Considering a sequence of event in a workplace for an employee with a Total-Worked-Hours of 58 hours and Frequency-of-Injury of 4.8.

From Figure 2, the input membership function (IMF) for the variable "Total-Worked-Hours" is 0.8 $(\mathrm{WH}-7)(\mu \mathrm{WH}-7$ (Total-Worked-Hour $)=0.8)$ and $0.2(\mathrm{WH}-14)(\mu \mathrm{WH}-14($ Total-Worked-Hour $)=0.2)$. From Figure 3, the IMF for the variable "Frequency-of-Injury" is 0.7 (HE) ( $\mu \mathrm{HE}$ (Frequency-ofInjury $)=0.7)$ and $0.3(\mathrm{IE})(\mu \mathrm{IE}($ Frequency-of-Injury $)=0.3)$.

Combining these, the following four logical inference reports are suitable:

If (Total-Hours-Worked is WH-7) and (Injury_Frequency is HE) then (Workplace-Unsafe_Rating is Very_High)

If (Total-Hours-Worked is WH-7) and (Injury_Frequency is IE) then (Workplace-Unsafe_Rating is High)

If (Total-Hours-Worked is WH-14) and (Injury_Frequency is HE) then (Workplace-Unsafe_Rating is High)

If (Total-Hours-Worked is WH-14) and (Injury_Frequency is IE) then (Workplace-Unsafe_Rating is Low)

Each of the rules was first determined with fuzzy logic to perform inference by assessing the connotation of the premises of the rules. To ascertain the suitability of each rule (matching), the inference mechanism distinguish which rules are ON (i.e., if its premises MF) $\mu$-premise [TotalWorked-Hour, Frequency-of-Injury] $>0$. The inference engine combined the recommendations of all the rules to come up with a single conclusion. The final stage was defuzzification, which operated on the implied fuzzy set (output fuzzy set) produced by the inference mechanism and connected the effects to produce the "most certain" Unsafe ratings of the workplace. As shown in the rule viewer (Figure 5), the final output rating for a worker with 'Total-Worked-Hours of 58 and sustained Injury in 4.8 times is 0.0679 . The "unsafe level" of the work station is interpreted using Table 3 as 'Very High'.

The rule viewer shown in figure 6 demonstrates an illustration of the complete fuzzy inference system. Each rule is a row of plots, and each column is a variable. When a user specifies the two input values in the space provided at the interface of APWAPES, a new calculation is performed as soon as the variables are posted, and the user can see the complete fuzzy inference process performed. The rule viewer allows the user to interpret the entire fuzzy inference process at once.

\subsection{Quality verification test for APWAPES}

Table 5 presents data on 20 selected work stations involving 20 employees. Each of the subjects had more than 2 years of working experience on their current job. Total hours worked and the numbers of injury sustained during the hours as reported by each subject are stated. Column 4 and 5 are the accidents rating and meanings respectively for each of the workplaces derived by using 
EME aforementioned in equation (1). Column 6 and 7 reported the accident rating predictions of the developed expert system and the interpretations of the output using Table 3 respectively.

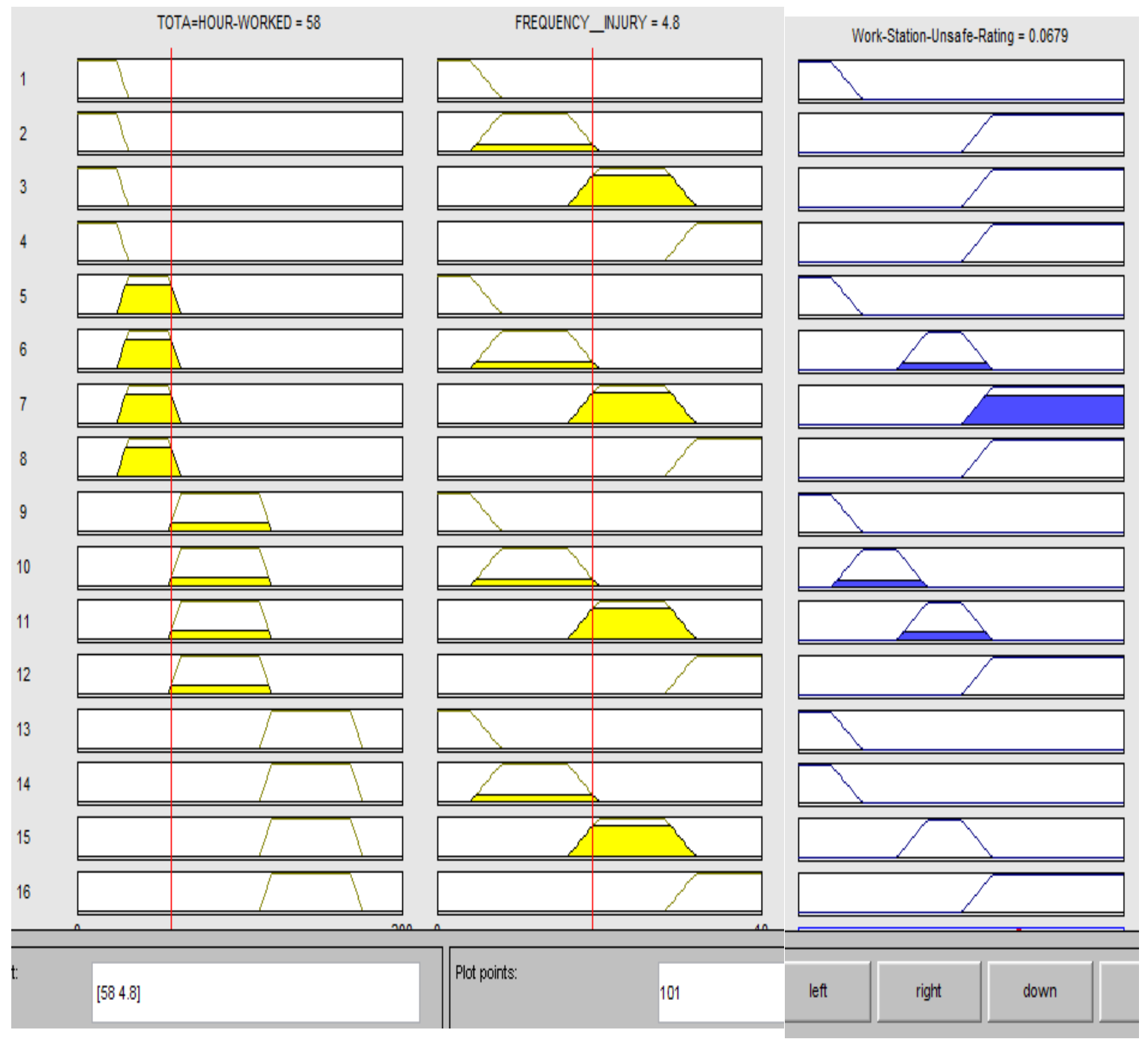

Figure 6: Rule viewer of the whole fuzzy inference process

The values generated using EME ranged between 0.01 and 0.1 while APWAPES system predicted in the range of 0.01 and 0.08 . In fourteen (14) cases, the EME predicted either High' or 'Very high' rating and in a similar trend, APWAPES system equally predicted either 'Very high' or 'High' rating' in all the 14 cases representing 100\% likeness of the two media. In cases 5, 9, 11, 14 and 17 the EME suggested 'Low' rating while APWAPES also predicted 'Low' ratings in 9, 11 and 14 but 'High' for cases 5 and 17 . This also represents $60 \%$ conformity. On the average, the EME value was $0.06 \pm 0.03$ and that of APWAPES system was $0.05 \pm 0.02$ both of which is interpreted as "very high'. In the case of sample 20, the interpretation of the APWAPES as 'Very Low' agreed with the view of Yusuf et al., [26] that in three days, a man is not expected to sustain injury more than one time. The total hour worked was 15 and this is still within the stated limit. 
Table 5: Variables measured, EME computation results, APWAPES predicted values and linguistic interpretations for 20 evaluated workers and workplaces

\begin{tabular}{rcccccc}
\hline $\begin{array}{c}\text { Subjects/ } \\
\text { Work } \\
\text { Stations }\end{array}$ & $\begin{array}{c}\text { Total } \\
\text { Hours } \\
\text { Worked }\end{array}$ & $\begin{array}{c}\text { Accident } \\
\text { Counts }\end{array}$ & $\begin{array}{c}\text { EME } \\
\text { rating }\end{array}$ & Meaning & $\begin{array}{c}\text { APWAPES } \\
\text { Rating }\end{array}$ & Meaning \\
\hline 1 & 24 & 2 & 0.08 & Very High & 0.05 & Very High \\
2 & 130 & 5 & 0.04 & High & 0.05 & High \\
3 & 45 & 2 & 0.04 & High & 0.05 & High \\
4 & 80 & 7 & 0.09 & Very High & 0.05 & High \\
5 & 160 & 5 & 0.03 & Low & 0.05 & High \\
6 & 32 & 3 & 0.09 & Very High & 0.05 & High \\
7 & 54 & 5 & 0.09 & Very High & 0.08 & Very High \\
8 & 128 & 5 & 0.04 & High & 0.05 & High \\
9 & 75 & 2 & 0.03 & Low & 0.03 & Low \\
10 & 104 & 6 & 0.06 & Very High & 0.05 & High \\
11 & 66 & 2 & 0.03 & Low & 0.03 & Low \\
12 & 48 & 5 & 0.10 & Very High & 0.08 & Very High \\
13 & 72 & 7 & 0.10 & Very High & 0.05 & High \\
14 & 96 & 2 & 0.02 & Low & 0.03 & Low \\
15 & 112 & 1 & 0.01 & Very Low & 0.01 & Very Low \\
16 & 10 & 1 & 0.10 & Very High & 0.08 & Very High \\
17 & 165 & 5 & 0.03 & Low & 0.05 & High \\
18 & 52 & 4 & 0.08 & Very High & 0.05 & High \\
19 & 65 & 5 & 0.08 & Very High & 0.05 & High \\
20 & 15 & 1 & 0.07 & Very High & 0.01 & Very Low \\
Mean \& Standard Deviation & $\mathbf{0 . 0 6 \pm 0 . 0 3}$ & & $\mathbf{0 . 0 5} \pm \mathbf{0 . 0 2}$ & \\
\hline & & & & & &
\end{tabular}

\subsubsection{Correlation test between EME and APWAPES outputs}

After comparing the result of values generated by EME with that of the APWAPES for correlation strength using Spearman's rho, a significant correlation was found as $r=0.710, p<.01$. The coefficient of determination of 0.710 suggested $71 \%$ variability.

\subsubsection{Independent samples $t$-test between EME and APWAPES}

The t-test to determine the mean difference between the EME and APWAPES found that EME showed a statistically significantly higher level of ratings $(0.60 \pm 0.30, \mathrm{SEM}=0.004)$ compared to APWAPES $(0.50 \pm 0.02, \mathrm{SEM}=0.007) \mathrm{t}(38)=1.613, \mathrm{p}=0.115$. However, the groups' means were not significantly different, because the value of "Sig. (2-tailed)" was greater than 0.05 .

Zadeh-Fard et al. [31] reported that efforts to reduce occupational hazards are yet to satisfactorily improve on occupational health and safety among workers in many industries. Serious injuries and death are still on the increase yearly. Roy [32] reported five most common workplaces' office hazards common in many industries: slips, trips and falls; ergonomic injuries (other injuries related to posture and repetitive movement), eye strain; fire safety; indoor air quality. In furtherance to efforts at improving occupational health and safety, APWAPES was proposed in this study to predict the unsafe level of work stations using injury-counts and total-hours-worked. APWAPES was tested with scenarios from different work stations. Comparisons between the EME and APWAPES showed that the groups' means predicted values of the two media were not significantly different and the linguistic interpretations were also similar. Determining the level of safety is vital to ascertain the level of indifference of many workplaces to the safety standards and/or negligence of ergonomics implementations existing in many work places. It also helps to identify unsafe work environment [26]. 
APWAPES was proposed in this study to help determine the level of safety of any work station where man interacts with machines and/or where manual material handling occurs.

If the prediction of the system indicates that accident rates are on the increase, the task method and/or workstations can be redesigned by implementing necessary ergonomics design capable of reducing the continual exposure of workers to one or more risk factors for accidents. World Health Organization [11] stated that industrial ergonomists recognize that engineering, work practice and administrative controls are the primary means of reducing employee exposures to occupational hazards. Hence workstations and work methods are to be designed according to human capabilities and limitations in line with applications of ergonomics principles. The costs of ignoring these basic principles may include: injuries and occupational diseases, increased absenteeism, higher medical and insurance costs, increased probability of accidents and errors, higher turnover of workers, less production output, lawsuits, low-quality work, less spare capacity to deal with emergencies [33].

The results obtained from using APWAPES and the comparison with EMEs were satisfactory. The few weaknesses recorded for APWAPES may be due to the limited inputs variables and issues in the dataset, which tends to reduce the accuracy of the predictions, especially in cases 5 and 17 where APWAPES prediction was higher than that predicted by the EME.

There are uncertainties in the occurrence of work stations' injuries depending on the individual worker, works environment and many other factors. This uncertainty in the data and in the evaluation process can be handled by the proposed fuzzy based expert system approach, as stated by Zadeh [20]. Considering the classification of injury frequency of 4 , this value fits into "Increased Events (IE)" with a membership degree of 1.0. The fuzzy approach considered the inherent uncertainties of the classification process, such as in the case of injury frequency of 4.1, which simultaneously fit into "Increased Event" and "High Event" with 1.0 and 0.2 membership degrees respectively.

APWAPES can find applications in any work place where hazards occur among all categories of employees most especially where there are man-machine interactions and manual material handling. The ergonomics device is recommended as capable of helping to create awareness for the need to put measures in place at reducing accidents' rate in any work activities. However, in the future efforts, the inclusion of more variables like accidents' severity and fatality can be considered for improvement of the model.

\section{CONCLUSION}

This study developed an expert system named Accident Prone Work Stations Prediction Expert System (APWAPES) to forecast unsafe level of occupational work station using "injuries count" and "total hours worked" as inputs variables. The expert system was developed using fuzzy logic technique. The Spearman's rho correlation coefficient between the existing mathematical models and APWAPES was found to be strong with the means of predicted values of the two methods not significantly different. The linguistic interpretations of the two devices were also similar. APWAPES can find applications in any work place where hazards occur among all categories of employees most especially where there is man-machine interaction and/or where there is manual material handling. The ergonomic device is capable of helping managers, in any industry, to measure work activities prone to accidents. This will assist in putting ergonomics measures in place at improving occupational health and safety among workers.

\section{REFERENCES}

[1] Shikdar A.A., Hadhrami M.A., (2005) "Operator Performance and Satisfaction in an Ergonomically Designed Assembly Workstation" The Journal of Engineering Research, vol.2 number-1(69-76).

[2] Deros B.M., Khamis N.K.(2011) "An ergonomics study on assembly line workstation design". American Journal of Applied Sciences 8 (11):1195-1201 
[3] Gurunath, V. S. and Jadhav, V.S. (2012). Ergonomic analysis of an assembly workstation to identify time consuming and fatigue causing factors using application of motion study" International Journal of Engineering and Technology Vol. 4(4) 2012 pp 220-227

[4] Washington State Department of Labor and Industries (2002) Office Ergonomics Practical solutions for a safer workplace. Available from http://www.lni.wa.gov/IPUB/417-133000.pdf

[5] Peden M, McGee K, Sharma G. (2002) The injury chart book. A graphical overview of the global burden of injuries. Geneva: Department of Injuries and Violence Prevention, Noncommunicable Diseases and Mental Health Cluster, World Health Organization.

[6] International Labor Organization. Work-related fatalities reach 2 million annually 2002. Available from: http://www.nieuwsbank.nl/en/2002/05/24/K016.htm. Accessed March 20 2015.

[7] Larsson TJ, Field B. The distribution of occupational injury risks in the Victorian construction industry. Saf Sci. 2002;40(5):43911.

[8] Galal.A Ali, (2010)." Traffic Accidents and Road Safety Management: A Comparative Analysis And Evaluation in Industrial, Developing, And Rich -Developing Countries". 29thSouthafrican Transport Conference (SATC2010) ISBN: 978-1-920017-7-7, Pretoria, South Africa.

[9] Battaglia, M., Frey, M. And Passetti, E. (2014). Accidents at Work and Costs Analysis: A Field Study in a Large Italian Company. Ind Health. 2014 Jul; 52(4): 354-366.

[10] World health organization (WHO) (1994). Global strategy on occupational health for all: The way to health at work. Recommendation of the second meeting of the WHO Collaborating Centres in Occupational Health, 11-14 October 1994, Beijing, China. Available

[11] World Health Organization (2001). Occupational health; A manual for primary health care workers. available from http://www.who.int/occupational_health/regions/en/oehemhealthcareworkers.pdf

[12] Christer, H. and Bodhi, P. (2000) Occupational Safety and Health in Developing Countries http://nile.lub.lu.se/arbarch/arb/2000/arb2000_17.pdf

[13] Pokorádi, L. (2010). Application Of Fuzzy Set Theory For Risk Assessment. Journal of KONBiN Vol.3 (14) 2010 pp 188-196

[14] Krause, U. (2000). A discrete nonlinear and non-autonomous model of consensus formation. Communications in difference equations, 227-236.

[15] Mallet, D. G., Bagher-Oskouei, M., Farr, A. C., Simpson, D. P. and Sutton, K. J. (2013). A mathematical model of Chlamydial infection incorporating movement of Chlamydial particles. Bulletin of mathematical biology, 75(11), 2257-2270.

[16] Murray, J.D., 2002. Mathematical Biology, I: An Introduction. Springer

[17] Tara-Louise B. (2017). Mathematical Modelling Of Worker Interactions And The Impact On Workplace Safety. Available From Https://Eprints.Qut.Edu.Au...

[18] Kamil, B., Juraj, V., Dagmar, V.(2013) Risk Analysis In Managerial Process And Fuzzy Approach. Transport and Telecommunication Vol. 14(3), 214-222

[19] DeReus, N.M. (1994). Assessment of benefits and drawbacks of using fuzzy logic:, especially in fire control systems. Available from www.dtic.mil

[20] Zadeh L.A. (2009). Toward Extended Fuzzy Logic - A First Step, Fuzzy Sets and Systems Vol. 160(21), p. 3175 -3181 (DOI: 10.1016/j.fss.2009.04.009)

[21] LÁSZLÓ, P O. (2002) Fuzzy logic-based risk assessment, AARMS Security. Vol 1(1) 63-73

[22] Bansal, A., 2011. Trapezoidal Fuzzy Numbers (a,b,c,d): Arithmetic Behaviour. International Journal of Physical and Mathematical Sciences, Volume 2(1), pp 39-44

[23] Omar, A. M. A., Aous Y. A., Balasem, S. S.( 2015). Comparison between the Effects of Different Types of Membership Functions on Fuzzy Logic Controller Performance International journal of Emerging Engineering Research and Technology Vol 3(3) pp 76-83

[24] MathWorks, 2002. Fuzzy Logic Toolbox User's Guide (version 2). Available online at: www.mathworks.com, Accessed on 12 September 2013 Smita, 2013 
[25] Adeyemi H. O., Adefemi A. A., Akinyemi O. O., Adefemi O. A. (2016) A ShovelingRelated Pain Intensity Prediction Expert System For Workers' Manual Movement Of Material International Journal of Technology. Vol. 7(4), Pp 540-552

[26] Yusuf, T. A., Sanusi, O. M., Adeyemi, H. O. (2016). A Model for Determining the Safety Level of Occupational Work Using Accidents and Injuries Measurement Parameters: A Review Journal of Engineering Studies and Research, Vol. 22(1), pp 1-6.

[27] Jang, J.S.R., Sun, C.T., 1996. Neuro-fuzzy and Soft Computing: A Computational Approach to Learning and Machine Intelligence. Prentice-Hall, Inc. ,New York

[28] Liu, F., Geng, H. and Zhang, Y. Q. (2005). Interactive fuzzy interval reasoning for smart web shopping, Applied Soft Computing (5): 433-439.

[29] Pokorádi L.: Systems and Processes Modeling, Campus Kiadó, Debrecen, 2008, pp. 242. (in Hungarian)

[30] Yen, J, Langari, R (1999) Fuzzy Logic: Intelligence, Control, and Information. Prentice-Hall, pp. $223-226$

[31] Zadeh-Fard, N., Schuh, A., Rashedi, E., Camelio, J.A., (2015). Risk assessment of occupational injuries using accident severity grade, Safety Science, 2015, vol. 76, p. 160167.

[32] Roy, M. (2017). Five Common Office Hazards to Prevent. Available from https://www.shrm.org/resourcesandtools/hr-topics/risk- management/pages/common-officehazards.aspx

[33] Health and Safety Executive (2013) Health and safety at work: A trade union priority. Available from www.ilo.org/wcmsp5/groups/public/---... 